\title{
As Representações Sociais dos Profissionais de Saúde Mental acerca do Modelo de Atenção e as Possibilidades de Inclusão Social'
}

\section{Social Inclusion Practices: professionals' social}

representations about the mental health assistance model'

\author{
Adriana Leão \\ Terapeuta ocupacional, mestre e doutoranda em Enfermagem na \\ Universidade de São Paulo. \\ Endereço: Av. Dr. Enéas de Carvalho Aguiar, 419, Cerqueira Cesar, \\ CEP 05403-000, São Paulo, SP, Brasil. \\ E-mail: drileaoळusp.br

\section{Sônia Barros} \\ Enfermeira, Professora Associada do Departamento de Enferma- \\ gem Materno-Infantil e Psiquiátrica da Escola de Enfermagem da \\ Universidade de São Paulo e Assessora de Gabinete da Secretaria \\ de Estado da Saúde de São Paulo. \\ Endereço: Av. Dr. Enéas de Carvalho Aguiar, 419, Cerqueira Cesar, \\ CEP 05403-000, São Paulo, SP, Brasil. \\ E-mail: sobarrosळusp.br \\ I Este artigo é parte da dissertação de mestrado intitulada "As práti- \\ cas de inclusão social: o desafio para os serviços de saúde mental", \\ de Adriana Leão, sob orientação da Prof Dr Sônia Barros, na Escola \\ de Enfermagem da Universidade de São Paulo. \\ Financiamento: CNPq - Conselho Nacional de Desenvolvimento \\ Científico e Tecnológico, processo: 135289/2005-0.
}

\section{Resumo}

Os Centros de Atenção Psicossocial (CAPS) são considerados dispositivos estratégicos para a mudança de modelo de atenção em saúde mental e apresentam proposições que vão ao encontro dos conceitos da Reabilitação Psicossocial. Buscou-se compreender na pesquisa realizada, como ocorrem as práticas de inclusão social voltadas para as pessoas com a experiência do sofrimento psíquico, no intuito de contribuir para a avaliação deste serviço, considerado um importante avanço no processo da Reforma Psiquiátrica Brasileira. 0 objeto de estudo são as representações sociais dos profissionais sobre práticas de inclusão social realizadas pelos serviços substitutivos em saúde mental. Utilizamos como conceitos norteadores da pesquisa a Reabilitação Psicossocial e a desinstitucionalização italiana. Os dados coletados, por meio de entrevistas semi-estruturadas, foram submetidos à análise do discurso, a partir da qual foi possível reconhecer algumas categorias empíricas, dentre as quais, sobre o modelo de atenção em saúde mental, tratada neste artigo. A análise das categorias empíricas foi realizada sob a ótica da representação social. Dentre os resultados obtidos, observamos que os discursos revelaram concepções representativas do modelo psiquiátrico tradicional. Tais representações podem vir a ser superadas a partir de uma maior clareza do projeto institucional do CAPS e de discussões dentro das equipes interdisciplinares.

Palavras-chave: Inclusão social; Serviço de saúde mental; Reabilitação psicossocial. 


\section{Abstract}

Psychosocial Attention Centers (CAPS) are considered strategic devices for changing the assistance model concerning mental health and present proposals that involve concepts of Psychosocial Rehabilitation. This research study aimed to understand how social inclusion practices for people who have experienced psychological suffering occur, and also to contribute to the evaluation of this service, as it is considered an important advance in the process of Brazilian Psychiatric Reform. The objects of the study are the professionals' social representations on social inclusion practices that are performed by the substitutive mental health services. The guiding concepts of this study are Psychosocial Rehabilitation and the Italian deinstitutionalization. The data, collected by means of semi-structured interviews, were submitted to discourse analysis, from which it was possible to recognize empirical categories. One of them is the mental health assistance model, which is studied in this article. The analysis of the categories was carried out according to the view of Social Representation. Among the results, it was possible to observe that the discourses revealed concepts that represent the traditional psychiatric assistance model. These representations can be overcome through a higher clarity of CAPS' institutional project and discussions within the interdisciplinary teams.

Keywords: Social inclusion; Mental Health Assistance Model; Psychosocial Rehabilitation.

\section{Os Centros de Atenção Psicossocial: desafios e possibilidades para a promoção da inclusão social}

Os Centros de Atenção Psicossocial - CAPS têm se destacado dentro do contexto da Política de Assistência à Saúde representando um dos avanços significativos da Reforma Psiquiátrica. Ao desempenharem o papel de articuladores da rede comunitária de cuidados em saúde mental, apresentando-se também como um equipamento substitutivo, os CAPS constituem, aliados a outros programas e ações, a principal estratégia do Ministério da Saúde para reverter o modelo de atenção centralizado na assistência hospitalar psiquiátrica.

Os CAPS têm por objetivo oferecer às pessoas portadoras de sofrimento psíquico um tratamento que alia o acompanhamento clínico e os cuidados de reinserção social de seus usuários por meio do acesso ao trabalho, ao lazer, pelo exercício dos direitos civis, bem como pela construção ou reconstrução dos laços comunitários e familiares (Brasil, 2004). As ofertas desse serviço, de acordo com Saraceno (1999), apresentam proposições que vão ao encontro dos conceitos preconizados pela Reabilitação Psicossocial.

Um dos principais desafios da Reforma Psiquiátrica encontra-se exatamente neste ponto, visto que a exclusão social é em essência um problema de teor político, estando diretamente vinculada ao aspecto econômico, devido à precarização do emprego, assim como à desagregação familiar e social. No caso de pessoas portadoras de transtornos mentais severos e persistentes, a exclusão social pela via do trabalho é ainda mais delicada, em decorrência sobretudo dos estigmas atribuídos à doença, acrescido ao fato do desemprego apresentar-se como um problema até mesmo para pessoas em condições "normais" de produtividade e competitividade.

De acordo com Castel, o processo de exclusão social pode designar a situação de todos aqueles que se encontram "fora dos circuitos vivos das trocas sociais" (1997, p. 20). Assim, a exclusão social não se restringe apenas à desintegração do mercado de trabalho mas refere-se também a uma ruptura nos laços sociais e familiares. Essa dissociação que inclui o vínculo social foi denominada de "desfiliação" por Castel (1989). 
De acordo com Demo (2002), no regime capitalista a inclusão social deve ocorrer pela vinculação ao mercado de trabalho, apresentando-se mais estrutural e garantida do que pela via da assistência. Para esse autor, a inserção social "exige muito mais do que assistência, sobretudo inserção laborial e supremacia da cidadania" (p. 7). Diante dessa problemática, no que concerne à assistência, a Reabilitação Psicossocial, enquanto restituição ao acesso dos direitos de cidadania, necessita contemplar a dimensão dos meios de produção, pois somente dessa maneira é possível reverter a imagem de improdutiva e desprovida de direitos que a pessoa portadora de transtorno mental frequentemente carrega (Vianna e Barros, 2002).

Os CAPS, sendo um serviço destinado a promover a Reabilitação Psicossocial, avançam em direção à construção de um outro modelo de atenção, em substituição aos serviços hospitalares psiquiátricos que têm por objeto de intervenção a doença mental e não a pessoa em seu contexto de vida. Contrariamente, o projeto do CAPS apresenta como preocupação central o "sujeito e sua singularidade, sua história, sua cultura e sua vida quotidiana” (Brasil, 2004, p. 14).

Se por um lado temos os progressos no processo da Reforma Psiquiátrica, por outro, estão presentes os problemas decorrentes dessa nova modalidade de assistência, que devem ser questionados e problematizados em busca de respostas sempre parciais, dada a dinamicidade da realidade. Através de resultados de pesquisas realizadas em alguns CAPS, supomos que esses serviços têm enfrentado certas dificuldades no que se refere à Reabilitação Psicossocial, por ainda centralizarem as ações em atendimentos clínicos e ambulatoriais e em menos proporção nas práticas de reinserção social (Tavares e col., 2003; Andreoli e col., 2004).

Diante dessa conjuntura, e considerando também a importância de apreender alguns dos limites e das potencialidades para promover a inclusão social das pessoas que passaram pela experiência do sofrimento psíquico no modelo proposto pela Reforma Psiquiátrica, é que foi realizada a pesquisa de mestrado que deu base ao presente texto, cujo objeto de estudo são as representações sociais que uma categoria de atores desse processo, no caso os profissionais, possuem acerca das práticas de inclusão social inseridas nessa outra perspectiva de modelo de atenção em saúde mental.

A conduta dos profissionais e as ações realizadas, refletem a ideologia - que não se desvincula da linguagem - presente no cotidiano dos serviços substitutivos e que propõe-se a estimular processos de autonomia e de inclusão social dos seus usuários. A importância das representações sociais está no fato de que elas expressam as condições reais vivenciadas e apresentam "núcleos positivos de transformação e de resistência na forma de conceber a realidade" (Minayo, 1998, p. 173).

Anteriormente à realização da coleta de dados, o projeto de pesquisa foi submetido ao Comitê de Ética e Pesquisa da Escola de Enfermagem da Universidade de São Paulo (CEP-EEUSP), conforme a Resolução nº 196 de 10/10/1996, do Conselho Nacional de Saúde, a qual dispõe sobre as normas de pesquisa envolvendo seres humanos. 0 projeto obteve a aprovação por meio do processo $n^{0}$ 461/2005 de 31/o8/2005.

Neste artigo buscamos apresentar um dos resultados da pesquisa, a saber: as concepções dos profissionais acerca do novo modelo de atenção representado pelos CAPS, modelo este no qual encontram-se inseridos e consideram-se envolvidos com as práticas de inclusão social.

\section{Percurso Metodológico}

Para tratar do objeto desse estudo - as representações sociais dos profissionais acerca das práticas de inclusão social - a abordagem mais adequada é a pesquisa qualitativa que deve ser entendida como uma tentativa de obter profunda compreensão dos significados e definições da situação tal como as pessoas nos apresentam. Essa abordagem parte do pressuposto de que o mundo está permeado de significados e símbolos e que a intersubjetividade é um ponto de partida para captar reflexivamente os significados sociais (Minayo, 1998).

A desinstitucionalização, segundo a perspectiva da Psiquiatria Democrática italiana, e a Reabilitação Psicossocial foram os conceitos eleitos como referência nesse estudo, por apresentarem proposições que fundamentam as práticas de inclusão social.

Compreendemos o termo "Reabilitação Psicosso- 
cial”, conforme definição fornecida pela Organização Mundial da Saúde, como um processo e não uma técnica, que tem como objetivo oferecer aos indivíduos inadaptados em decorrência do transtorno mental, condições para exercer suas potencialidades e capacidades de forma independente na sociedade (OMS, 2001). Assim, a construção da cidadania, bem como a restituição da contratualidade do indivíduo nos aspectos da rede social, do habitat e do trabalho como valor social, são os eixos norteadores do processo de Reabilitação Psicossocial. Tendo como finalidade a ampliação dos espaços de negociação para a realização das trocas sociais, os profissionais de saúde mental devem estar atentos a estes pontos (Saraceno, 1999).

A recusa e a crítica à função do hospital psiquiátrico e da psiquiatria, bem como a proposição de novas formas de lidar com o sofrimento psíquico, tiveram ênfase com o movimento social denominado Psiquiatria Democrática Italiana, no início da década de 1960, cujo representante mais importante foi Franco Basaglia. A proposta de desinstitucionalização desse movimento representa a desmontagem dos aparatos científicos, tecnológicos, jurídicos e culturais criados para solucionar a questão da doença mental pela via da exclusão.

O tema central da desinstitucionalização na perspectiva basagliana é o confronto das questões psiquiátricas com as contradições sociais. Assim, é colocada em discussão a restituição dos direitos, a complexidade das necessidades, as possibilidades das pessoas acometidas pelo transtorno mental, bem como a finalidade da instituição psiquiátrica em relação à estrutura social (Nicácio e col., 2005). Dessa forma, a proposta no processo de desinstitucionalização é deslocar o olhar para a "existência sofrimento" em relação ao corpo social, retirando o indivíduo dos "parênteses" colocados pela psiquiatria. A finalidade desse processo é a "invenção de saúde" e a "reprodução social do paciente”, buscando a sua autonomia, a produção de sentido e de sociabilidade (Rotelli, 2001).

Como cenário desse estudo, elegemos o Centro de Atenção psicossocial - CAPS II, localizado na cidade de São Carlos, Estado de São Paulo, para um estudo de caso. Foram considerados sujeitos da pesquisa os funcionários que estiveram presentes numa reunião de equipe, ocasião onde foi apresentada a proposta do estudo, bem como aqueles outros profissionais indicados pelos próprios entrevistados e que se consideraram envolvidos nas atividades de inclusão social.

A coleta de dados foi realizada através de onze entrevistas semi-estruturadas que foram gravadas e imediatamente transcritas. 0 instrumental teórico utilizado para a análise dos textos foi a Análise do Discurso, uma proposta criada pelo francês Michel Pêcheux, na década de 1960. Essa abordagem possibilita um entendimento do texto de forma mais aprofundada, levando em consideração a realidade social e histórica em que foi produzido o discurso. Na área da saúde, a Análise do Discurso possibilita compreender o discurso de forma dinâmica, sendo possível reconhecer e interpretar as concepções acerca de um dado objeto conforme o contexto de sua produção (Vianna e Barros, 2003).

A análise dos discursos foi realizada obedecendo a seguinte seqüência proposta por Fiorin (apud Vianna e Barros, 2003): leitura repetida dos discursos; análise das várias possibilidades de leitura do texto; análise da estrutura do texto, procurando depreender as figuras e os temas; identificação dos valores, crenças e concepções dos sujeitos; identificações das argumentações presentes no discurso e reconhecimento da emergência das categorias empíricas, a partir dos temas depreendidos. Para Minayo (1998), as categorias empíricas são responsáveis por captar as contradições no aspecto empírico da realidade a ser pesquisada.

Para a análise das categorias empíricas foi utilizada a representação social que, conforme Minayo (1998), é definida como sendo um conjunto de conceitos, afirmações e explicações, utilizado pelas pessoas para a compreensão e construção da realidade, e que possibilita a valorização do conhecimento popular, o senso comum. Nesse estudo, verifica-se a importância da representação social como categoria de análise da concepção das práticas de inclusão social dos projetos assistenciais, através da visão de mundo dos profissionais que compõem a equipe do CAPS, pois o senso comum, objeto de estudo das representações sociais, deve ser visto como conhecimento legítimo e motor das transformações sociais. A análise deste conhecimento é capaz de revelar não a lógica e a coerência, mas sim a natureza contraditória na qual estão inseridos os atores sociais (Spink, 1993). 
As Representações Sociais dos Trabalhadores de Saúde Mental: os

\section{CAPS compondo um novo modelo de atenção}

De acordo com Costa-Rosa e col. (2003, p. 19), as transformações da prática assistencial em saúde mental, na lógica do Modo Psicossocial, passam a ter influências no Brasil a partir da década de 1980, quando o termo psicossocial designa os "novos dispositivos institucionais (Centros de Núcleos de Atenção psicossocial - CAPS e NAPS) que aspiram a outra lógica, outra fundamentação teórico-técnica, que não mais as do paradigma psiquiátrico". Utilizamos aqui o conceito de paradigma definido por Kuhn como sendo um "conjunto de leis, conceitos, modelos, analogias, valores, regras e critérios para a avaliação de teorias e formulações de problemas, e princípios metafísicos”. (Kuhn, 970, apud Barros, 2004, p. 30).

Nessa modalidade de atenção, a finalidade das ações assistenciais interdisciplinares incide sobre a inclusão social das pessoas com transtornos mentais. Assim, o olhar direciona-se para outros aspectos da vida do indivíduo e suas necessidades de ordem biológica, social e econômica, não mais tendo a cura como meta das intervenções e sim o exercício da contratualidade, para além das limitações impostas pelo sofrimento psíquico.

Ao optar por estruturar as diretrizes políticas da saúde mental e suas práticas dessa forma, assume-se o conceito de desinstitucionalização referente a seu aspecto de crítica e negação do paradigma psiquiátrico (Costa-Rosa e col., 2003). Nesse sentido, a concepção de desinstitucionalização e os preceitos da Reabilitação Psicossocial "perpassam todo o discurso de modelo assistencial que vem sendo implantado e tem sido um norte e um argumento para a política dessa área" (Cambraia, 2004, p. 104). Assim os CAPS atuais, inspirados nos CAPS e nos NAPS da década de 1990, tornaram-se, com base na Portaria 336/o2, uma modalidade de serviço.

Assim, dentre as categorias empíricas identificadas na análise dos dados da pesquisa, apresentamos neste artigo o modelo de atenção, seguindo a definição de Campos (1992, p. 16), que o considera como sendo um "conceito que estabelece intermediações entre o técnico e o político", configurando-se em algo que não é apenas técnico e nem somente político. 0 modelo de atenção deve ser um projeto composto por "interesses e necessidades da sociedade, das noções disciplinares, de diretrizes políticas e dos modos de gestão dos sistemas públicos”.

As concepções dos profissionais acerca do modelo de atenção giraram em torno dos seguintes temas apreendidos: as diretrizes políticas na área de saúde mental, o modelo de atenção representado pelos CAPS, as necessidades dos recursos humanos e a concepção de doença mental.

\section{Diretrizes políticas}

A análise dos discursos revelou algumas críticas às diretrizes colocadas pela política nacional de saúde mental, no que se refere à redução dos leitos psiquiátricos. A ausência de um serviço para atendimento de emergência na cidade de São Carlos revela a necessidade do hospital psiquiátrico e a sua defesa enquanto um espaço potencialmente terapêutico:

E2 Não é o hospital que vai fazer a exclusão do paciente, quem vaifazer a exclusão é a mentalidade de quem está trabalhando lá dentro.

$\varepsilon_{9} O$ hospital pode ser uma coisa muito ruim. $\varepsilon$ muito ruim porque deixaram que ele chegasse a ser uma coisa ruim, mas poderia ser perfeitamente muito bom e continuar sendo um hospital.

No entanto, a presença e a expansão dos CAPS são vistas como facilitadoras do processo de inclusão social, diferentemente do modelo de atenção centrado no hospital psiquiátrico, conforme notamos nos discursos seguintes:

$\varepsilon_{3} O$ CAPS já é a porta da inclusão social porque não tinha, era hospital psiquiátrico ou fundo de casa amarrado.

Notamos, pela análise das frases temáticas, uma contradição: por um lado, considera-se que o CAPS, por si só, represente a inclusão social, e que o hospital psiquiátrico é um dos produtores da exclusão (frase E3) o que reforça a concepção de que a internação exclui porque isola, afasta da família e impede a circulação das pessoas pelos espaços. Por outro lado, a exclusão não é produto do equipamento de saúde (frase E2 acima), havendo então uma defesa desta insti- 
tuição na rede assistencial (frase E9 acima). A afirmação da necessidade do hospital especializado mostra a representação da psiquiatria e de sua forma de intervenção, a internação como a maneira de tratamento mais segura e que, portanto, deve ser mantida desde que transformada.

De acordo com Birman e Costa (1994, p. 50), a transformação da instituição psiquiátrica em espaço terapêutico significa o próprio tratamento dos sintomas psicotizantes do hospital, pois assim é possível proporcionar saúde mental para os indivíduos que a ele recorrem. Contudo, é preciso questionar a terapêutica dessa instituição diante de sua função social: "O que representa esta fórmula ambígua de terapêutica de um espaço social (o hospital) como condição de possibilidade da Saúde mental?".

Segundo os discursos abaixo, a implementação do CAPS na cidade de São Carlos foi acompanhada de mudanças na gestão de outras áreas dos serviços públicos, o que foi pontuado como benéfico, no intuito de efetivar relações intersetoriais, sobretudo com centros comunitários, para promover a inclusão social:

E11 Começou a reavaliar tudo, mudar o modelo e esse modelo não foi mudado só na Saúde mental, foi junto à [Secretaria da] Cidadania, começou a desmontar aquela forma assistencialista...

$\varepsilon_{9}$ Essa inclusão dos centros comunitários no projeto, só que eles [coordenação dos centros comunitários] nunca aceitaram isso. Agora com as chefias novas estão tentando pra ver se consegue, aí vamos ter um instrumento um pouco mais aforado de inclusão social, que é a oficina de trabalho.

Pudemos verificar ainda, que a intersetorialidade como uma das bases para o desenvolvimento das práticas de inclusão social, apareceu nos discursos de maneira recorrente. É consenso na literatura sobre o assunto que para a construção de rede de atenção e rede social, a intersetorialidade é um dos aspectos primordiais. Nesse sentido, ressaltamos a necessidade de interlocução das demais políticas públicas com a área da saúde mental.

\section{0 modelo de atenção}

Na cidade de São Carlos, anteriormente à implantação do CAPS, em 2002, o atendimento à saúde mental era basicamente ambulatorial. De acordo com as frases temáticas, a implantação desse modelo de atenção enfrentou inicialmente resistências de outros atores do município, como por exemplo, dos funcionários das Unidades Básicas de Saúde, da direção dos centros comunitários e de alguns trabalhadores da área de saúde mental. Os discursos apontaram ainda, as famílias como um dos pólos de resistência:

E11 Só vamos conseguir fazendo com que ela [a família] entenda a mudança de modelo, fazendo com que entenda que hoje ela não fica mais de folga porque ela estava acostumada no outro modelo que ficava de folga...

Mas, contraditoriamente a essa culpabilização, o sofrimento das famílias é reconhecido:

E11 Também para elas o internar é um sofrimento, ela também sofre com a crise, sofre com esse processo e o CAPS possibilitou a estabilização disso.

A afirmação de que as famílias não se responsabilizavam pelo seu membro, delegando a tutela para o hospital psiquiátrico, é um dos reflexos dos papéis de culpabilização e de cumplicidade atribuídos às mesmas no modelo psiquiátrico tradicional (Saraceno, 1999). Observamos assim, que o paradigma manicomial, que tem por objeto de intervenção a doença mental e não a pessoa e suas demandas, permeia os discursos dos profissionais no serviço de saúde mental, que visa funcionar de acordo com um outro paradigma, ou seja, o psicossocial.

O risco maior para o processo de transformação do modelo de atenção é justamente a reprodução, nos serviços substitutivos, das "bases teórico-práticas do modelo psiquiátrico clássico, que fundou a noção de doença mental como sinônimo de desrazão e patologia, que fundou o manicômio como lugar de cura e que fundou a cura como ortopedia e normalização" (Amarante e Torre, 2001, p. 33).

Para que seja fornecido um suporte adequado às famílias, que tenha sentido e responda às implicações da problemática do sofrimento mental, é preciso que os profissionais sejam capacitados e conheçam as representações que as famílias possuem sobre as experiências singulares de convivência com o seu familiar adoecido, o que desenvolverá um outro olhar para a conduta dos familiares.

Outra representação social ancorada no paradigma manicomial é a concepção do CAPS em si como a inclusão social: 
$\varepsilon_{3}$ O que é o CAPS hoje? O CAPS é inclusão social, não é? Ele é inclusão social, é o ponto de partida, o fato do paciente estar saindo dos hospitais e vindo para cá, os usuários já estão tendo a inclusão social na própria família.

A segregação que o hospital psiquiátrico representa é uma das faces da exclusão social, uma vez que o usuário ao não conseguir exercer suas trocas sociais e permanecer numa situação de vida muitas vezes sem significados ou transformações concretas que produzam movimentos de inclusão social, pode estar excluído desse processo. Desse modo, Salles (2005, p. 212), na pesquisa em que procurou analisar o cotidiano das pessoas no período entre as hospitalizações psiquiátricas, concluiu que, mesmo não estando internada, a pessoa com transtorno mental continua excluída em decorrência da ideologia manicomial que "ultrapassa os muros do manicômio e passa a ser concretizada nas relações do paciente mesmo quando ele está fora da internação, na comunidade".

Por outro lado, também é compreendido nos discursos, que o CAPS não é um sinônimo de inclusão social, mas uma estratégia para estimular esse processo ao enfrentar a cultura estigmatizante, ao buscar construir rede social, ao estimular a autonomia do usuário, ao evitar internações e possibilitar outras formas de tratar o sujeito:

$\varepsilon_{1}$ O objetivo do CAPS realmente é esse, é o carro chefe a inclusão social do paciente.

Salientamos que se o CAPS não executar seu projeto institucional de acordo com os princípios que a Reforma Psiquiátrica lhe atribui, rumo à inclusão social, a mudança de modelo ficará comprometida, atravancada, reproduzindo a lógica baseada na exclusão, não mais pela contenção física ou química, mas sim pela não viabilização de ações imprescindíveis a esse processo. Nessa direção, as frases temáticas denunciam a necessidade de investimentos, caso contrário, exercerão o papel de meros reprodutores de ações assistencialistas:

E9 A tendência se continuar do jeito que está é a transformação do CAPS em pequenos manicômios. A verdade nua e crua, se não der verbas, se não se transformar isso em prioridade e se não se encontrar formas de comunicar...
No Congresso Brasileiro de CAPS, realizado em 2004 , foi constatado que esse equipamento tem sido alvo de críticas por parte de alguns militantes do movimento da Reforma Psiquiátrica, assim como de trabalhadores e gestores que pedem a atenção para o risco de "manicomialização" desses serviços. Diante desse quadro, é preciso um mecanismo de avaliação interdisciplinar a fim de compreender e analisar os processos de gestão e assistência dos CAPS. Um instrumental metodológico de avaliação deve contemplar a constituição plural e interdisciplinar desses serviços, e nesse intuito defende-se que esse instrumento seja construído a partir da esfera da saúde coletiva, juntamente com a saúde mental (Onocko-Campos e Furtado, 2006).

Outro subtema analisado refere-se à localização do serviço. A implantação do CAPS junto a recursos comunitários representa uma inversão visível da atenção hospitalar, pois os dispositivos hospitalocêntricos funcionam geralmente em lugares afastados, onde os seus internos mantêm-se alheios ao que acontece na cidade. A instalação desses serviços em “casas”, bairros ou centros de cidade, possibilita que os usuários, ao terem acesso à vizinhança e a estabelecimentos comerciais - "irem e virem da padaria, comprarem guloseimas no baleiro do ponto do ônibus, enfim, vivenciarem a rotina do lugar - desenvolvam em si e na comunidade o sentimento de pertencimento" (Guljor, 2003, p. 138). Contraditoriamente a esta proposição sobre a localização do serviço substitutivo próximo a recursos comunitários, é referida na frase temática abaixo (E9) a necessidade de um lugar mais afastado, o que está de acordo com a implantação de hospitais psiquiátricos, sobretudo, em regiões isoladas da cidade, o que faz parte da lógica manicomial e não da proposta dos CAPS:

E9 Um espaço mais amplo, térreo, uma chácara, onde o pessoal tenha um espaço, onde possa ter uma quadra. Um espaço fundamental porque nós temos pacientes que ficam andando o dia todo, esquizofrênicos.

Basaglia (2005, p. 50) descreve as pessoas institucionalizadas, cujos sintomas apresentados são confundidos muitas vezes com a própria doença e constituem uma síndrome: "a apatia, o desinteresse e o lento e monótono caminhar de cabeça baixa, sem rumo, pelos corredores ou pelos pátios fechados". 
No entanto, acreditamos que os CAPS têm a possibilidade de romper com essa lógica, a partir do momento que concretamente "promovam o protagonismo de cada usuário frente à sua vida". Para isso, tem por objetivo a reconstrução dos vínculos sociais, familiares e comunitários, devendo estimular a autonomia gradativamente para que o usuário não desenvolva dependência ao tratamento e ao espaço do serviço. A alta, nesse sentido, é conseqüência da estruturação dessa rede social, da condição psíquica e do projeto terapêutico desenvolvido com o usuário (Brasil, 2004).

Através dos textos também foram reveladas as possibilidades encontradas para a inclusão social, as quais se apresentam próximas aos conceitos de Reabilitação Psicossocial:

$\varepsilon_{2}$ O MOVA é uma questão belíssima. (...) [A professora] luta com dificuldades muito grandes, mas ela é o embrião de alguma coisa que sim, vai existir no futuro, mostra que é possível.

$\varepsilon_{7}$ Nós temos uma usuária que (...) quando teve alta foi para o centro comunitário do bairro dela, aonde participou fazendo pães, salgadinhos, ela mesma fazia, aprendeu a fazer, depois vendia, então isso para ela foi muito bom.

Tais práticas referem-se ao estabelecimento de relações intersetoriais, cujos resultados observados foram: aquisição de carteirinha para gratuidade nas passagens de ônibus; projetos envolvendo a alfabetização - MOVA (Movimento de Alfabetização de Adultos); o retorno a uma atividade produtiva a partir de encaminhamentos para centros comunitários e cooperativas do município; o estabelecimento de relações, trocas afetivas com a comunidade, por meio de festas ou eventos comemorativos e o uso dos recursos comuns à vizinhança do CAPS; o estímulo ao desenvolvimento de uma consciência mais crítica dos usuários e a percepção de si, por meio de uma oficina de jornal.

\section{Necessidades dos recursos humanos}

Outro tema analisado nos discursos referem-se às necessidades dos recursos humanos no que diz respeito à formação profissional e a insuficiência de profissionais no serviço. Não pretendemos nos aprofundar na ampla discussão em torno do trabalhador de saúde mental, mas evidenciar as representações dos sujei- tos acerca deste tema no momento da mudança do modelo de atenção.

As frases temáticas revelam que os profissionais identificam dificuldades no cotidiano do serviço, devido à ausência de formação dos profissionais de saúde mental para a atuação na perspectiva da atenção psicossocial, necessitando de maiores conhecimentos, tanto no que se refere ao aspecto clínico, quanto às questões psicossociais, no sentido de realizar ações com os usuários que, de fato, sejam promotores de inclusão social. Desse modo, reproduzem em seus discursos a necessidade de formação e aperfeiçoamento.

$\varepsilon_{2}$ Pouco conhecimento, pouco estudo continuado sobre o que é a doença mental.

$\varepsilon_{7}$ Sinto essa dificuldade agora de saber o que poderíamos fazer para estar pondo eles para fora. $\varepsilon u$ não sei como agir.

A capacitação e a supervisão dos recursos humanos em saúde mental é que consolidarão uma nova abordagem de prática assistencial, tendo em vista que "prédios novos e portas abertas não garantem projetos terapêuticos que respeitem a autonomia de sujeitos portadores de transtornos mentais", nem a sua inclusão social (Oliveira e Alessi, 2003, p. 38).

Um outro entrave assinalado na área de recursos humanos foi a insuficiência do número de funcionários e a necessidade de inclusão de outros profissionais para a realização de oficinas, visitas domiciliares, abordagem com as famílias e resolução de situações jurídicas.

$E_{1}$ Não tem tempo para pegar mais uma oficina e fazer, acho que precisaria de mais terapeutas, de mais psicólogos...

A promoção da inclusão social dos usuários do CAPS esbarra no desafio de suprir essas demandas dos recursos humanos. Para que seja efetivada a mudança paradigmática e não apenas a reformulação de antigos princípios, é necessário estabelecer rupturas nas questões conceituais e práticas que envolvem os profissionais nos novos serviços de atenção à saúde mental (Amarante e Torre, 2001).

\section{Concepção de doença mental}

De acordo com Minayo (1998, p. 176), as representações de saúde/doença "manifesta de forma específica as concepções de uma dada sociedade como um todo. 
Cada sociedade tem um discurso sobre saúde/doença e sobre o corpo, que corresponde à coerência ou às contradições de sua visão de mundo", que irá refletir na estruturação social.

As representações sociais dos profissionais com relação ao transtorno mental são relevantes para a mudança de modelo de atenção ao compreendermos que a concepção que

temos de um dado objeto determina a maneira como lidamos com ele. Esse tema surgiu nos discursos, com considerações em torno das características do transtorno mental, de algumas possíveis causas, das dificuldades decorrentes, da cura, da relação de normalidade e da impossibilidade para estar no mercado produtivo.

O desencadeamento das crises nos transtornos mentais foi atribuído ao descontrole, pela insatisfação de alguma necessidade, como a de ser ouvido (frase E6) e a solução estaria também pautada nas reflexões e direcionamento impulsionado pela vontade (frase E8):

E6 Às vezes dependendo de alguma coisa que eles perguntam pra gente, o que aconteceu na casa deles ninguém dá atenção, é essa hora que a pessoa pira.

$\varepsilon 8$ Se pensasse dava um pulo, todos nós temos uma força interior contra os males. (...) Não precisava estar aí à toa, pra lá, pra cá, assistindo televisão, assistindo filme, jogo...

Os discursos acima são representações do senso comum influenciadas pelas concepções propostas no século XIX. Na obra do francês Esquirol, a doença mental tinha como base de existência o comportamento moral e social do indivíduo com reflexo nos hábitos, no caráter, nas ações e nas paixões. Como conseqüência, restituir a condição de normalidade significa sintonizar a razão e a vontade (Barros e Egry, 2001).

Outro aspecto da doença mental depreendido dos discursos refere-se à cura. As características de incurabilidade, instabilidade no curso da doença e de cronificação (frases E1 e E9) têm repercussão no discurso dos entrevistados e, no que diz respeito à inclusão social, isto é assinalado como um dos agravantes para o retorno ao mercado de trabalho (frase E9), e, portanto os indivíduos com a experiência do sofrimento mental permanecem sob a insígnia da incapacidade e da improdutividade (frase E9), bem como é marcada a desvalorização do seu poder contratual.
Estas são concepções representantes da cultura manicomial ainda presente.

E1 Não é porque estabilizou que a pessoa está pronta para ser jogada lá na rotina da sociedade e fazer tudo que uma pessoa dita normal faz, ele vai ter sempre as barreiras dele, do que pode e do que ele não pode...

$\varepsilon_{9}$ Não tenho muitas ilusões também não. Muitas não, na verdade eu não tenho quase nenhuma (riso), de que vão ter uma inclusão social plena, que são seres produtivos. Não são. Não adianta a gente ficar sonhando que vai porque não vai.

E9 A partir do segundo surto a tendência é a cronificação e a pessoa, não adianta a gente se iludir que vai voltar a ser produtiva como era antes, a ser aceita numa empresa, não vai.

Para a medicina, a cura significa a solução definitiva dos problemas de saúde, a restituição do funcionamento regular do organismo. De acordo com Jucá (2005), o quadro de esquizofrenia representa a incurabilidade e, conseqüentemente, a falência da psiquiatria quanto ao restabelecimento da saúde mental de forma plena. Nesse caso, o que se alcança é um estado de "quase normalidade" em que há uma imposição permanente de limites.

Por outro lado, começar a conceber a doença mental como uma "patologia da liberdade", cujo indivíduo acometido perde os direitos de ir e vir, de ter opinião e credibilidade, de ser respeitado em seus desejos e de ter trabalho (Osinaga, 2004, p. 10), direciona o olhar para o sujeito que sofre e assim, a terapêutica deve ter por objetivo ampliar a capacidade de autonomia, pois isto é representativo e sinônimo de cura (Campos, 1992).

A existência da doença, bem como a necessidade de tratamento, não são negados, o que se coloca em discussão são as formas de lidar com a pessoa em sua “existência-sofrimento". Nesse caso, a desinstitucionalização a ser perseguida nos serviços substitutivos é aquela que considera que o problema a ser solucionado é a remoção de barreiras para a reprodução de sentidos, de vida e de sociabilidade, o que significa um processo de singularização e ressingularização das pessoas (Rotelli e col., 2001).

Nessa perspectiva, contrariando as últimas afirmações anteriores (E1 e E9) a respeito da incurabili- 
dade, cronificação e descrédito, as possibilidades aparecem timidamente no discurso seguinte:

E11 Lógico que não tem cura, ele vai tomar remédio, é um transtorno mental severo e tal, mas ele lida com essa realidade com muita tranqüilidade porque tem a questão do valor social, do reconhecimento da família e da sociedade, da própria autoestima dele que tudo contribui positivamente.

O sofrimento psíquico começa também a ser compreendido sob uma outra abordagem, em que o sujeito é visto muito além de sua doença, buscando explorar suas potencialidades. Estabelecer ações pautadas na perspectiva da inclusão social demanda a "desconstrução da desesperança” e dessa forma, a substituição da "profecia sobre o futuro centrada na doença pelo reconhecimento das diferenças individuais, da variedade de tipos de rede de pertinência dos sujeitos" (Valentini e Vicente, 2001, p. 51).

Nos discursos analisados foi possível notar que alguns conceitos e afirmações em torno da doença mental estão de acordo com a proposição de um novo modelo de atenção. Entretanto, também são desveladas nas frases temáticas muitas concepções representativas do modo tradicional psiquiátrico. Temos a convivência de diferentes visões de mundo acerca da doença e, consequentemente, dos meios de lidar com o indivíduo, que certamente se expressam na prática cotidiana do serviço.

\section{Considerações Finais}

Para que os serviços substitutivos de saúde mental cumpram com o seu objetivo de inclusão social, de acordo com as diretrizes da Reforma Psiquiátrica Brasileira, devem buscar ações que possibilitem e estimulem a realização de trocas sociais, principalmente em sua rede social nuclear - a família, que solicita dos profissionais sensibilidade para lidar com o seu sofrimento sem culpabilizações; devem buscar ainda o enfrentamento ao estigma e a produção de autonomia da pessoa acometida pelo transtorno mental, também pela via do trabalho.

A mudança de modelo de atenção em saúde mental está atrelada a essas práticas que vão além da área da saúde e demandam debates mais intensos em torno da complexidade do sistema de saúde como um todo, das relações intersetoriais, bem como das condições sócio-econômicas, no que se refere ao mercado de trabalho e da insuficiência das Políticas Sociais, entre outros aspectos.

Constatamos, além disso, que o momento de transição dos paradigmas está refletido nos discursos por meio de compreensões das práticas representativas do modelo de atenção pautado no hospital psiquiátrico, juntamente com novas perspectivas de atenção baseadas no modo psicossocial.

Barros (2004) afirma que os CAPS, principais dispositivos de mudanças do modelo de atenção, enfrentam um momento de transição paradigmática, do paradigma dominante, o psiquiátrico, para o paradigma emergente, a saúde mental, sendo necessários novos discursos, bem como práticas inovadoras para tratar o transtorno mental sob outra lógica. Dessa forma, a explicitação das ideologias presentes no serviço de saúde mental pode contribuir positivamente para a avaliação e posterior transformação dos discursos, e, posteriormente, da realidade em que estão inseridos os atores envolvidos no processo de inclusão social das pessoas com experiência do sofrimento psíquico.

Nesse sentido, as práticas consideradas de inclusão social, dentro do serviço substitutivo, que são, por sua vez, condizentes com as representações do modelo tradicional psiquiátrico podem ser superadas a partir das discussões dentro das equipes interdisciplinares. Assim, o projeto institucional que sustenta as ações do CAPS também deve apresentar clareza em suas diretrizes.

\section{Referências}

AMARANTE, P.; TORRE, E. H. G. A constituição de novas práticas no campo da atenção psicossocial: análise de dois projetos pioneiros na Reforma Psiquiátrica no Brasil. Saúde em Debate, Rio de Janeiro, v. 25, n. 58, p. 26-34, maio/ago. 2001.

ANDREOLI, S. B. et al. Utilização dos Centros de Atenção Psicossocial (CAPS) na cidade de Santos, São Paulo. Cadernos de Saúde Pública, Rio de Janeiro, v. 20, n. 3, p. 836-844, maio/jun. 2004.

BARROS, S. Concretizando a transformação paradigmática em saúde mental: a práxis como horizonte para a formação de novos trabalhadores. 2004. Tese de livre-docência- Escola de Enfermagem da Universidade de São Paulo, São Paulo, 2004. 
BARROS, S.; EGRY, E. Y. O louco, a loucura e a alienação institucional: o ensino de enfermagem sub-judice. Taubaté: Cabral, 2001.

BASAGLIA, F. Escritos selecionados em saúde mental e reforma psiquiátrica. Rio de Janeiro: Garamond, 2005.

BIRMAN, J.; COSTA, J. F. Organização de instituições para uma psiquiatria comunitária. In: AMARANTE, P. (Org.). Psiquiatria social e reforma psiquiátrica. Rio de Janeiro: Fiocruz, 1994. p. 41-72.

BRASIL. Ministério da Saúde. Saúde mental no SUS: os Centros de Atenção Psicossocial. Brasília, DF, 2004.

CAMBRAiA, M. Política de saúde mental no Estado de São Paulo: o cenário das mudanças ocorridas entre 1990 e 2004. 2004. Tese (Doutorado em Saúde Pública) - Faculdade de Saúde Pública da Universidade de São Paulo, São Paulo, 2004.

CAMPOS, G. W. S. Modelos de atenção em saúde pública: um modo mutante de fazer saúde. Saúde em Debate, Rio de Janeiro, v. 37. p. 16-19, dez. 1992.

CASTEL, R. Da indigência à exclusão, a desfiliação precariedade do trabalho e vulnerabilidade relacional. In: LANCETTI, A. (Org.). Saudeloucura1. São Paulo: Hucitec, 1989. p. 21-48.

CASTEL, R. As armadilhas da exclusão. In: BÓGUS, L.; YAZBEK, M. C.; BELFIORE-WANDERLET, M. (Org.). Desigualdade e a questão social. São Paulo: EDUC, 1997. p. $15-48$.

COSTA-ROSA, A.; LUZIO, C. A.; YASUI, S. Atenção psicossocial: rumo a um novo paradigma na saúde mental coletiva. In: AMARANTE, P. (Coord.). Archivos de saúde mental e atenção psicossocial. Rio de Janeiro: NAU, 2003. p. 13-44.

DEMO, P. Charme da exclusão social. 2. ed. Campinas: Autores Associados, 2002.

GULJOR, A. P. F. Os centros de atenção psicossocial: um estudo sobre a transformação do modelo assistencial em saúde mental. 2003. Dissertação (Mestrado em Saúde Pública) - Escola Nacional de Saúde Pública, Fundação Oswaldo Cruz, Rio de Janeiro, 2003.
JUCÁ, V. J. S. A multivocalidade da cura na saúde mental: uma análise do discurso psiquiátrico. Ciência e Saúde Coletiva, São Paulo, v. 10, n. 3, p. 771779, 2005 .

MINAYO, M. C. S. O desafio do conhecimento: pesquisa qualitativa em saúde. 5. ed. São Paulo: Hucitec, 1998.

NICÁCIO, F.; AMARANTE, P.; BARROS, D. D. Franco Basaglia em terras brasileiras: caminhantes e itinerários. In: AMARANTE, P. (Coord.). Archivos de saúde mental e atenção psicossocial 2. Rio de Janeiro: NAU; 2005. p. 195-214.

OLIVEIRA, A. G. B.; ALESSI, N. P. A reforma psiquiátrica e o processo de trabalho das equipes de saúde mental. Revista Paulista de Enfermagem, São Paulo, v. 22, n. 1, p. 31-42, jan./abr. 2003. OMS - ORGANIZAÇÃO MUNDIAL DA SAÚDE. Organização Panamericana de Saúde. Relatório sobre a saúde no mundo 20o1: saúde mental: nova concepção, nova esperança. Genebra, 2001.

ONOCKO-CAMPOS, R. T.; FURTADO, J. P. Entre a saúde coletiva e a saúde mental: um instrumental metodológico para avaliação de Centros de Atenção Psicossocial (CAPS) do Sistema Único de Saúde. Cadernos de Saúde Pública, Rio de Janeiro, v. 22, n. 5 , p. 1053-1062, mar. 2006.

OSINAGA, V. L. M. Estudo comparativo entre os conceitos de saúde e de doença mental e a assistência psiquiátrica, segundo portadores e familiares. 2004. Tese - Escola de Enfermagem de Ribeirão Preto da Universidade de São Paulo, Ribeirão Preto, 2004.

SALLES, M. Internação em hospital psiquiátrico: o (des)caminho para vivência do cotidiano e da inserção social. 2005. Dissertação (Mestrado em Enfermagem) - Escola de Enfermagem da Universidade de São Paulo, São Paulo, 2005.

SARACENO, B. Libertando identidades: da reabilitação psicossocial à cidadania possível. Belo Horizonte: Te Cora, 1999.

ROTELLI, F. A instituição inventada. In: NICÁCIO, M. F. S. (Org.). Desinstitucionalização. 2. ed. São Paulo: Hucitec, 2001. p. 89-99. 
ROTELLI, F.; LEONARDIS, O.; MAURI, D.

Desinstitucionalização, uma outra via. In: NICÁCIO, M. F. S. (Org.). Desinstitucionalização. 2. ed. São Paulo: Hucitec, 2001. p. 17-59.

SPINK, M. J. P. O conceito de representação social na abordagem psicossocial. Cadernos de Saúde Pública, Rio de Janeiro, v. 9, n. 3, p. 300-308, jul./set. 1993.

TAVARES, C. M. M. et al. Análise de implementação de tecnologias de cuidar em saúde mental na perspectiva da atenção psicossocial: Escola Anna Nery. Revista de Enfermagem, Rio de Janeiro, v. 7, n. 3 , p. 342-350, ago. 2003.
VALENTINI, W. A. H.; VICENTE, C. M. A reabilitação psicossocial em Campinas. In: PITTA, A. M. F. (Org.). Reabilitação psicossocial no Brasil. São Paulo: Hucitec, 2001. p. 48-54.

VIANNA, P. C. M.; BARROS, S. O processo saúde doença mental: a exclusão social. REME Revista Mineira de Enfermagem, Belo Horizonte, v. 6, n. 1/2, p. 86-9o,jan./dez. 2002.

VIANNA, P. C. M.; BARROS, S. A análise do discurso: uma revisão teórica. REME Revista Mineira de Enfermagem, Belo Horizonte, v. 7, n. 1, p. 56-6o, jan./ jul. 2003 . 